\title{
ANÁLISE OBSERVACIONAL EM UNIDADE DE INTERNAÇÃO PEDIÁTRICA: UM ESTUDO DE CASO
}

\author{
Cássio de Almeida LIMA ${ }^{1}$ \\ Áquila Silva MARTINS ${ }^{1}$ \\ Eleny Pereira SILVA ${ }^{1}$ \\ Guilherme Henrique Azevedo dos REIS ${ }^{1}$ \\ Amanda Fonseca Moura LAFETÁ ${ }^{1}$ \\ Patrícia Fernandes do PRADO ${ }^{2}$ \\ Renata Patrícia Fonseca GONÇALVES ${ }^{2}$ \\ Claudia Danyella Alves Leão RIBEIRO ${ }^{2}$ \\ Osvaldina Gonçalves Siqueira de SOUZA ${ }^{3}$
}

Recebido em: 30/05/2014 - Aprovado em: 30/06/2014 - Disponibilizado em: 30/07/2014

\begin{abstract}
RESUMO
O presente trabalho teve como objetivo apresentar a análise observacional de uma unidade de internação pediátrica, na perspectiva do cuidado integral à criança e sua família. Trata-se de pesquisa descritiva, exploratória, observacional, do tipo estudo de caso. O estudo foi realizado por meio de uma visita na pediatria de um hospital universitário situado ao Norte do Estado de Minas Gerais, durante atividades práticas do Curso de Graduação em Enfermagem da Universidade Estadual de Montes Claros. Foram observados os ambientes da clínica, questões de funcionalidade, segurança e humanização. Verificou-se que alguns aspectos precisam ser readequados no setor conforme as recomendações das normas de estabelecimentos assistenciais de saúde vigentes. As adequações poderão contribuir para um ambiente terapêutico mais favorável à vivência de seus usuários, proporcionando-os maior conforto, segurança e qualidade da assistência.

Palavras-chave: Saúde da criança; Assistência integral à saúde da criança; Arquitetura hospitalar; Enfermagem pediátrica.

\section{OBSERVATIONAL ANALYSIS IN A PEDIATRIC INTERNMENT UNIT: A STUDY CASE}

\begin{abstract}
This present study had as an objective to show an observational analysis of a pediatric internment unit, in the whole child care and its family. This is a descriptive, exploratory, observational research of the kind of study case. The study was done through a pediatric visit to a university hospital situated in the North of the State of Minas Gerais, during the practice activities of the Undergraduate Course of Nursing of the State University of Montes Claros. Clinic environment, functionality, safety and humanization were observed. Some aspects were verified to be adjusted in the sector due to the norm recomendation of the Health Assistance establishments. The adjustment can contribute to a favorable therapeutical environment for its users, offering confort, safety and assistence quality.

Keywords: Child Health; Whole Child Care; Hospital Architecture; Pediatric Nursing.

\footnotetext{
${ }^{1}$ Acadêmico do Curso de Graduação em Enfermagem da Universidade Estadual de Montes Claros (UNIMONTES). Montes Claros, MG, Brasil. E-mail: cassio-enfermagem2011@hotmail.com

${ }^{3}$ Enfermeira, Servidora do Hospital Universitário Clemente de Faria (HUCF). Montes Claros, MG, Brasil.
}

${ }^{2}$ Enfermeira. Professora Mestre do Departamento de Enfermagem da UNIMONTES. Montes Claros, MG, Brasil.
\end{abstract}




\section{INTRODUÇÃO}

Os espaços contemporâneos da saúde apontam para um novo desenho, baseado na relação mais humana com o usuário, em que todos os envolvidos no cuidado com a saúde são valorizados durante a concepção arquitetônica do edifício (OLIVEIRA, 2012).

As instituições de saúde, na atualidade, têm tido grande inquietação para que sua estrutura espacial esteja adequada conforme as normas e diretrizes preconizam. Nesse sentido, as enfermarias das clínicas devem estar adequadas para atender a todos os usuários e para as enfermarias da pediatria não é diferente. Esta deve estar preparada para garantir a assistência adequada não apenas para o público infantil, como também para os pais que acompanham seus filhos. Para tanto, atender os clientes infantis com equidade torna-se não somente um dever da instituição, como também um direito do usuário do serviço. Nessa lógica, a pediatria deve ser projetada a fim de lhe proporcionar maior conforto, segurança, privacidade, atividades recreativas e de humanização, entre outras (ROCHA, 2008; COSTA; MOMBELLI; MARCON, 2009; FURTADO et al., 2010).

$\mathrm{O}$ planejamento e a qualidade de projetos de edifícios destinados ao atendimento à saúde com racionalização, adequação e humanização dos espaços tornase de fundamental importância (BERGAN et al., 2009).
Nos espaços hospitalares, ao mesmo tempo em que o paciente está buscando recuperar sua saúde, ele sofre paralelamente interferências do meio, sejam elas físicas, químicas, biológicas, ergonômicas ou psicológicas, estando sujeitos a sensações como expectativa, ansiedade, desconfiança, insegurança, desânimo, tristeza e medo. Mais

ainda quando este paciente é uma criança, a hospitalização pode se configurar em um fenômeno estressante e traumatizante, pois nesse período a criança depara com vários desafios (DUTRA DE SOUSA et al., 2011).

Além da crise envolvendo a criança doente e sua família, retratada por vários fatores como: descontinuidade na satisfação das necessidades biológicas, psicológicas e sociais entre os membros da família; mudança no padrão do papel desempenhado pelos pais; aumento do grau de dependência da criança doente; o aparecimento do sentimento de culpa e a ansiedade na família, também podem ocorrer a compreensão do hospital como um ambiente estranho, que fomenta sofrimentos (DUTRA DE SOUSA et al., 2011).

O espaço físico-arquitetônico não deve ser mais um elemento estressante para a criança e seus familiares, visto todos os outros enfrentamentos que terão deparar durante a hospitalização. A arquitetura deverá contribuir para o bem-estar de ambos, propondo um local em que haja respeito, 
dignidade e conforto durante o processo de enfrentamento da doença. Entretanto, na prática, nem sempre essa preocupação se traduz em elementos concretos. Os estabelecimentos de saúde que atendem essa clientela, ainda não refletem a plena importância do espaço físico e da ambiência para a recuperação dos pacientes e também para os processos de trabalho mais eficientes (OLIVEIRA, 2012).

Segundo Bergan et al. (2009), quando o espaço é projetado para a criança, a hospitalização pode ser percebida mais positivamente, sendo um auxiliar no processo de cura. Assim, deve haver um empenho de todos para que se minimize a angústia física e psíquica em relação ao momento tão particular que estão vivenciando durante a internação. Nesse sentido, este estudo objetivou apresentar a análise observacional da unidade pediátrica de um hospital universitário, na perspectiva da atenção integral à criança e sua família.

\section{METODOLOGIA}

Trata-se de estudo descritivo, exploratório, de caráter observacional, do tipo estudo de caso. Teve como cenário a unidade pediátrica de um hospital universitário situado ao Norte do Estado de Minas Gerais. A instituição foi reconhecida pelo Ministério da Educação e Cultura (MEC) em 2005, como hospital de ensino, é pública e administrada com os recursos do Sistema Único de Saúde (SUS) e doações.

O levantamento de dados foi realizado através da observação da unidade por meio de uma visita a fim de analisar a relação do espaço físico da clínica com usuários, acompanhantes e profissionais de saúde da unidade, conforto ambiental, questões de funcionalidade, segurança e humanização. Utilizou-se um roteiro de observação para nortear o estudo.

O trabalho foi realizado por acadêmicos do $5^{\circ}$ período do Curso de Graduação em Enfermagem da Universidade Estadual de Montes Claros (UNIMONTES), no período de fevereiro de 2013, durante as atividades de interlocução teórico-prática da Unidade de Ensino Atenção Integral à Criança.

\section{RESULTADOS}

\section{Acesso}

O setor pediátrico atende crianças de 0 a 12 anos e 11 meses advindas de todo o Norte de Minas, Vale do Jequitinhonha e Sul da Bahia. Possui capacidade de atendimento para 20 leitos e localiza-se no primeiro pavimento do hospital, paralelamente entre a Clínica Médica A e Clínica Médica B e no mesmo corredor da Clínica Cirúrgica e do Serviço de Nutrição e Dietética da instituição.

A unidade situa-se em uma área que apresenta tráfego intenso de pessoas no corredor de circulação: profissionais de saúde 
do setor e de outras clínicas, pacientes de outros setores, acadêmicos de enfermagem e medicina, fisioterapeuta, dentre outras especialidades. Observou-se que não há um controle de entradas e saídas, o que gera um fluxo irrestrito, promovendo sensação de falta segurança, visto a facilidade de se adentrar na pediatria. O ideal seria que o fluxo de pessoas fosse controlado, visto que conforme a ANVISA deve haver uma preocupação de se restringir ao máximo os números desses acessos, com o objetivo de se conseguir um maior controle da movimentação no estabelecimento, evitando-se o tráfego indesejado em áreas restritas, o cruzamento desnecessário de pessoas e serviços diferenciados, além dos problemas decorrentes de desvios de materiais (BRASIL, 2002).

\section{Enfermarias}

Os leitos da pediatria estão distribuídos em 03 enfermarias coletivas, sendo uma composta de 07 leitos, 02 compostas de 06 leitos e 01 quarto de isolamento com 01 leito. As enfermarias atendem à demanda de internações não havendo separação por faixa etária ou por sexo, o que acarreta em constantes rearranjos de mobiliários, de acordo com o perfil dos pacientes no momento. Observou-se que os espaços entre os leitos são apertados e sem privacidade.
Em cada leito há um conjunto de mobília: uma cama ou berço de ferro pintado, sendo que somente os berços possuem grade de proteção lateral; uma mesinha de apoio, em ferro e com gaveta e uma poltrona reclinável para acomodação do acompanhante. Em cada enfermaria há uma televisão, um ramper para descarte de roupas sujas e um armário de ferro com escaninhos destinado a guarda de objetos pessoais dos pacientes e acompanhantes.

Em relação ao acabamento, as paredes são pintadas com tinta acrílica na cor verde claro, sendo o teto sem forro e com pintura na cor branca. O piso é escorregadio, sendo observado algumas ranhuras e frestas. Todas as enfermarias possuem abertura para o exterior através de uma janela em ferro e com vidro incolor, permitindo a circulação de ar e a entrada da luz do dia.

Cada enfermaria possui uma porta principal de madeira, revestidas de laminado que dá acesso ao corredor de circulação da unidade. Somente uma enfermaria possui porta com visor e outra enfermaria possui duas portas, sendo uma destinada ao acesso para a área externa de lazer do setor. Assim, o acesso dos usuários internados nos demais quartos da unidade para a área de lazer é realizado através dessa enfermaria, deixandoa mais agitada, barulhenta e com menos privacidade.

Verificou-se ausência de lavatório/pia para uso da equipe de assistência nas enfermarias, sendo disposto nestes 
ambientes um suporte de álcool gel. Observou-se também que as instalações elétricas como luminárias e tomadas não são suficientes assim como as instalações de gases medicinais canalizados.

O quarto de isolamento está situado na mesma área do posto de enfermagem e é delimitado por divisórias de material sintético e vidro que funciona como visor. Possui uma pequena antecâmera, um lavatório e um banheiro. A ventilação no local se dá por meio de uma janela com abertura para a área de lazer das crianças. Observou-se que o quarto não possui conforto higro-térmico e por estar localizado no mesmo ambiente do posto de enfermagem, infere-se que a iluminação artificial no centro do posto gera desconforto visual ao paciente e seu acompanhante causado pela incidência da luz no isolamento.

Com relação aos aspectos de
humanização não foram identificados
elementos decorativos com temas infantis
dentro das enfermarias, somente nas placas de
identificação das crianças nos leitos. Nesse
aspecto, a ambiência nas enfermarias poderia
ser melhorada, com espaços mais
aconchegantes e com mais referências lúdicas,
alegrando o ambiente e fazendo com este seja
um pouco mais familiar ao universo da
criança.

\section{Banheiros}

Na unidade visitada cada enfermaria é atendida por um banheiro para uso dos pacientes e acompanhantes. Cada um dos banheiros possui uma bancada em mármore com pia, uma bacia sanitária infantil e uma divisória em ardósia para o chuveiro. Cabe aqui ressaltar, que o banheiro é utilizado por pacientes de diferentes faixas etárias, sendo o uso da bacia infantil desconfortável aos pacientes maiores e acompanhantes. Observou-se que os banheiros não são equipados com barras de apoio, o piso é cerâmico, as paredes são revestidas com azulejo e as portas são em madeira revestidas de laminado, com abertura para dentro e com maçaneta. Segundo a RDC 50, as portas dos banheiros devem abrir para fora do ambiente, a fim de que sejam abertas sem necessidade de empurrar o paciente eventualmente caído atrás da porta e devem ter um puxador horizontal, associado à maçaneta.

\section{Recreação}

A clínica dispõe de uma área de recreação para as crianças com aproximadamente $10 \mathrm{~m}^{2}$. O espaço conta com piso em cerâmica na cor cinza e paredes são pintadas com temática infantil. Há ainda no local mesas retangulares com cadeiras e alguns brinquedos. O local também é utilizado para atividades dirigidas pela 
pedagogia hospitalar. A unidade conta com o suporte sócio-educativo e recreativo da escola hospitalar que fica situada em área externa a pediatria. É um ambiente colorido, alegre e aconchegante. Dispõe de uma brinquedoteca para atividades de recreação e sala com mesas e cadeiras para acompanhamento pedagógico das crianças em idade escolar. O local possui armários e prateleiras com jogos, brinquedos e livros. Existe ainda uma brinquedoteca móvel, que visa a atender as crianças que não podem se locomover até o local. A escola hospitalar abre diariamente, exceto finais de semana e feriados, no período de 07 às $13 \mathrm{~h}$.

\section{Posto de enfermagem e área administrativa}

Ambiente utilizado pela equipe de enfermagem e destinado também aos serviços administrativos do setor. Neste local há: um computador, um telefone, duas mesas de escritório, uma bancada em "L" em granito, com prateleiras inferiores e com duas cubas em aço inox, um armário com divisórias para armazenar os medicamentos de cada paciente e materiais de consumo, uma caixa com suporte de parede para descarte de material perfuro-cortante e um lavatório para uso da equipe de saúde da unidade. Esse lavatório não possui torneira do tipo que dispensa o contato das mãos quando do fechamento da água, não estando em conformidade com a recomendação da RDC 50. O piso e as paredes seguem o padrão das enfermarias e a ventilação é proporcionada por um peitoral/ janela sem visor na parede de acesso ao corredor de circulação do setor.

No posto existe ainda uma pequena área anexa, destinada à guarda de pertences dos funcionários e um pequeno vão com uma porta de passagem para a área de lazer do setor. Observou-se que o posto não está estrategicamente bem localizado entre as enfermarias.

\section{Prescrição médica}

Local em que são realizadas as prescrições médicas e ficam arquivados os prontuários dos usuários internados. Possui uma bancada em granito, uma mesa de reuniões, cadeiras, dois armários e um quadro onde são registrados os nomes das crianças internadas. A ventilação é proporcionada por um peitoral/ janela sem visor na parede de acesso ao corredor de circulação da unidade.

\section{Sala de procedimentos}

Área localizada ao lado do posto de enfermagem, destinada a realização de procedimentos e curativos. A sala também é utilizada para outras finalidades, como pesagem das crianças e passagem de plantão da equipe de enfermagem. Neste local há uma porta que dá acesso ao corredor da unidade e uma janela em ferro e com vidro incolor com 
abertura para a área de lazer. Neste ambiente há uma bancada com 02 balanças pediátricas, 01 balança com régua, 01 maca e 01 armário.

\section{Demais áreas de apoio}

A unidade visitada não possui área exclusiva para armazenar equipamentos e materiais, ficando muitos destes no corredor de circulação do setor e o local para depósito de materiais de limpeza (DML) é utilizado em comum com a clínica cirúrgica do hospital. Em relação aos demais ambientes de apoio que contemplam o programa arquitetônico recomendado pela RDC 50 para unidade de internação pediátrica, não foram verificados no setor espaço destinado ao ambiente de estar para pacientes, acompanhantes e visitantes, área para guarda de macas e cadeira de rodas e sanitário para funcionários. Infere-se que esses ambientes que são desejáveis, apesar de no momento não existirem, poderiam proporcionar um melhor funcionamento da unidade.

\section{Recomendações}

Sabe-se que os ambientes de pediatria devem ter características específicas de acordo com cada faixa etária, respeitando as atividades exercidas em cada uma das fases e enfatizando as relações que o cliente pediátrico estabelece com o seu entorno. A unidade de internação é o local onde, comumente, o usuário passa a maior parte do tempo e por isso deve-se ter atenção especial quanto aos elementos que constituem o ambiente (ROCHA, 2008).

Assim, atualmente se defende que há grande benefício na presença constante da mãe junto ao filho internado. Esses benefícios são tanto de ordem administrativa como social, porque a criança se reabilita mais rapidamente caso sua mãe esteja presente, torna-se mais comunicativa, as informações são obtidas de modo mais rápido e consequentemente se agiliza o tempo de atuação dos profissionais (MACHADO; MARTINS, 2002).

Por sua vez, o enfermeiro deve se comprometer a disponibilizar um momento para atender e ouvir o familiar, não somente estando atento às informações, mas também às queixas, dificuldades e oferecer apoio emocional e treinamento no que o familiar precisar para que o tratamento da criança seja eficaz (MURAKAMI; CAMPOS, 2011), além de atividades lúdicas (AZEVEDO et al., 2008).

\section{CONSIDERAÇÕES FINAIS}

Os resultados forneceram material para a reflexão acerca da importância de um espaço voltado para as crianças como auxílio no processo de cura. Alguns aspectos precisam ser readequados na unidade visitada, a fim de promover a melhoria das condições 
ambientais, permitindo o seu funcionamento adequado e tornando o ambiente mais seguro e mais agradável para os pacientes pediátricos, seus familiares e profissionais de saúde.

\section{REFERÊNCIAS}

AZEVEDO, D. M.; SANTOS, J. J. S.; JUSTINO, M. A. R.; MIRANDA, F. A. N.; SIMPSON, C. A. O brincar enquanto instrumento terapêutico: opinião dos acompanhantes. Revista Eletrônica de Enfermagem, Goiás, v. 10, n. 1, p. 137-44, 2008. Disponível em:

$<$ http://www.fen.ufg.br/revista/v10/n1/v10n1a 12.pdf>. Acesso em: 02 abr 2013

BERGAN, C.; BURSZTYN, I; SANTOS, C. O. M.; TURA, L. R. L. Humanização: representações sociais do hospital pediátrico. Revista Gaúcha de Enfermagem, Porto Alegre v. 9, n. 6, p. 223-229, 2009.

BRASIL. Ministério da Saúde. Agência Nacional de Vigilância Sanitária. Departamento de Normas Técnicas. Resolução RDC n⿳50, de 21 de fevereiro de 2002. Dispõe sobre o regulamento técnico para planejamento, programação, elaboração e avaliação de projetos físicos de estabelecimento assistenciais de saúde. Brasília; 2002.

COSTA, J. B.; MOMBELLI, M. A.; MARCON, S. S. Avaliação do sofrimento psíquico da mãe acompanhante em alojamento conjunto pediátrico. Estudos de Psicologia, v. 26, n. 3, p. 317-325, 2009.

DUTRA, D. S. L. et al. A família na unidade de pediatria: percepções da equipe de enfermagem acerca da dimensão cuidadora. Cienc. enferm, v. 17, 2011.

FURTADO, M. C. C.; MELLO, D. F.; PARADA, C. M. G. L.; PINTO, I. C.; REIS, M. C. G.; SCOCHI, C. G. S. Avaliação da atenção ao recém-nascido na articulação entre maternidade e rede básica de saúde. . Revista Eletrônica de Enfermagem, Goiás, v. 12, n. 4, p. 640-646, 2010. Disponível em: $<$ http://www.fen.ufg.br/revista/v12/n4/v12n4 a07>. Acesso em: 22 jan 2014.

MACHADO, MMP,; MARTINS, DG. A criança hospitalizada: espaço potencial e o palhaço. Boletim de Iniciação Científica em Psicologia. 2002;3(1):34-52.

MURAKAMI R, CAMPOS CJG. Importância da relação interpessoal do enfermeiro com a família de crianças hospitalizadas. Revista Brasileira de Enfermagem, Brasília, v. 64, n. 2,p. 254-260, 2011.

OLIVEIRA, J. S. Humanização em saúde: arquitetura em enfermarias pediátricas. Dissertação (Mestrado). Universidade Federal de Juiz de Fora, Juiz de Fora, 2012.

ROCHA, M. M. B. Detalhes arquitetônicos em unidades de internação pediátrica [monografia]. Faculdade de Arquitetura, Universidade Federal da Bahia; 2008. 